Article

\title{
The Validity of Functional Threshold Power and Maximal Oxygen Uptake for Cycling Performance in Moderately Trained Cyclists
}

\author{
Arne Sørensen $^{1, *}$, Tore Kristian Aune ${ }^{1}$, Vegar Rangul ${ }^{2}$ and Terje Dalen ${ }^{1}$ (D) \\ 1 Department of Physical Education and Sport Science, Faculty of Education and Arts, Nord University, \\ 7600 Levanger, Norway; tore.k.aune@nord.no (T.K.A.); terje.dalen@nord.no (T.D.) \\ 2 Faculty of Health Science, Nord University, 7600 Levanger, Norway; vegar.rangul@nord.no \\ * Correspondence: arne.sorensen@nord.no
}

Received: 28 August 2019; Accepted: 27 September 2019; Published: 1 October 2019

check for updates

\begin{abstract}
Cycling is a popular sport, and evaluation of the validity of tests to predict performance in competitions is important for athletes and coaches. Similarity between performance in sprints in mass-start bike races and in the laboratory is found, but, to our knowledge, no studies have investigated the relationship between laboratory measurements of maximal oxygen uptake $\left(\mathrm{VO}_{2 \max }\right)$ and functional threshold power (FTP) with performance in official mass-start competitions. The purpose of this study was to evaluate the validity of a $20 \mathrm{~min}$ FTP test and $\mathrm{VO}_{2 \max }$ as predictors for performance in an official mountain bike competition. Eleven moderately trained male cyclists at a local level participated in this study (age: $43 \pm 5.1$ years; height: $183.4 \pm 5.4 \mathrm{~m}$; weight: $84.4 \pm 8.7 \mathrm{~kg}$; body mass index: $25.1 \pm 2.1$ ). All subjects performed a $20 \mathrm{~min}$ FTP test in the laboratory to measure the mean power. In addition, the subjects completed an incremental test to exhaustion to determine $\mathrm{VO}_{2 \max }$. These two laboratory tests were analyzed together with the results from a $47 \mathrm{~km}$ mass-start mountain bike race, with a total elevation of $851 \mathrm{~m}$. A significant relationship was found between the mean relative power $(\mathrm{W} / \mathrm{kg})$ for the $20 \mathrm{~min}$ FTP test and performance time in the race $(r=-0.74$, $P<0.01)$. No significant correlation was found between $\mathrm{VO}_{2 \max }$ and cycling performance for these subjects $(r=-0.37)$. These findings indicate that a $20 \mathrm{~min}$ FTP test is a more valid test for prediction of performance in mass-start bike races than a $\mathrm{VO}_{2 \max }$ test for moderately trained cyclists.
\end{abstract}

Keywords: 20 min FTP; $\mathrm{VO}_{2 \max }$; mass-start mountain bike race; validity

\section{Introduction}

Cyclists are characterized by their ability to produce high power during competitions lasting from $30 \mathrm{~min}$ to $6 \mathrm{~h}$ [1]. In an attempt to control and evaluate the training progress, testing of physiological and performance-related variables is essential [1]. The considerable variability of cycling tests makes it difficult for athletes and coaches to choose the most appropriate one for predicting competition performance [2].

Maximal oxygen uptake $\left(\mathrm{VO}_{2 \max }\right)$ is probably the predictor that is tested the most for athletes in endurance-based sports. Testing of $\mathrm{VO}_{2 \max }$ is common because high oxygen uptake is an established indicator of aerobic endurance [3]. The use of changes in $\mathrm{VO}_{2 \max }$ as a marker for improvement in cycling performance is somewhat argued in the literature [2]. A high correlation between $\mathrm{VO}_{2 \max }$ and functional threshold power (FTP, i.e., the highest power a cyclist can maintain in a quasi-steady state without fatiguing for approximately $1 \mathrm{~h} \mathrm{[4])} \mathrm{was} \mathrm{found} \mathrm{when} \mathrm{testing} \mathrm{untrained} \mathrm{recreational} \mathrm{cyclists} \mathrm{and}$ moderately trained cyclists [5]. Similar correlations were found when investigating the relationship between peak power output (PPO), $\mathrm{VO}_{2 \mathrm{max}}$, and performance time in a $20 \mathrm{~km}$ time trial (TT) for trained 
cyclists [6]. However, no significant association was found between $\mathrm{VO}_{2 \max }$ and cycling time in a half Ironman (90 km bike race) or a full Ironman (180 km bike race) [7]. It was discovered that, despite no differences in $\mathrm{VO}_{2 \max }$ between groups, the "elite-national class" group performed a $40 \mathrm{~km}$ TT $10 \%$ faster than the "good-state class" group [8]. Research reported that $\mathrm{VO}_{2 \max }$ did not correlate with performance in a 20 or 90 min TT for highly trained cyclists [9]. In contrast to this, another study found moderately high and high correlations ( $r=0.61,0.79$ and 0.87 for 5,20 , and $60 \mathrm{~min}$, respectively) when examining the relationship between $\mathrm{VO}_{2 \max }$ and performance in moderately trained cyclists [10]. Research indicates that $\mathrm{VO}_{2 \max }$ is important for cycling performance at a moderate level, but, for high-performance athletes, there might be criteria for an optimal level of $\mathrm{VO}_{2 \max }$ beyond which any further increase does not lead to increased cycling performance [5]. An explanation for this notion could be that the difference in $\mathrm{VO}_{2 \max }$ for different performance levels is small, with values reported to be 70-75, 68-75, and 65-73 ml/kg/min among professional, elite, and amateur cyclists, respectively [2].

Cyclists depend on their ability to produce high levels of power. A high correlation is observed between absolute PPO measured during laboratory tests and power on the flat in a field TT [11-14]. Quod [15] found that power produced in a laboratory sprint test correlated highly with power in sprints during a mass-start competition. Absolute PPO is associated with performance time in a 20 min TT (mainly flat terrain) for well-trained cyclists [11], but this correlation is not found for cyclists at a moderate level [12]. During a $60 \mathrm{~min}$ laboratory TT, also called an FTP test, cyclists are instructed to generate as much power as possible for the entire hour. A shorter $20 \mathrm{~min}$ TT was found to be highly associated with performance in the $60 \mathrm{~min}$ TT [4]. Furthermore, large correlations $(r=0.61-0.88)$ were found between a $20 \mathrm{~min}$ FTP test (FTP20) and a $60 \mathrm{~min}$ FTP test (FTP60) on power output, heart rate, and oxygen uptake. The small difference between mean power during the FTP20 and FTP60 is argued to be due to a larger contribution of anaerobic metabolism in the FTP20 (for a review, see [16]); therefore, calculation of FTP is recommended by subtracting 5\% of mean power in the FTP20 to find FTP [16].

The body mass of cyclists is important in establishing the ability to perform over different terrains in road racing. Bigger cyclists have an advantage on flat terrain, whereas small cyclists perform better cycling up hills [17]. The highest energy cost over flat terrain is due to air resistance, and larger cyclists with higher absolute power achieve relatively lower air resistance than smaller cyclists [17]. When cycling up hills, overcoming gravity causes the highest energy cost, and air resistance is less because of the lower speed [17]. Tan and Aziz [18] suggest that absolute power is a good predictor of cycling performance on flat terrain, whereas high relative power is a better predictor for cycling performance up hills. Other studies report relative PPO and $\mathrm{VO}_{2 \max }$ to be the best predictors for uphill cycling performance $[19,20]$. In mountain bike races, the importance of high levels of $\mathrm{VO}_{2 \max }$ and PPO related to body mass was highlighted by several studies [21-23]. However, one study reported that for high-level cross-country off-road cyclists, submaximal levels of aerobic fitness at the respiratory compensation point were more decisive for performance than $\mathrm{PPO}$ and $\mathrm{VO}_{2 \max }$ [24]. Performance in mass-start bike races not only depends on physiological abilities but also on tactical decisions, among others. The advantage of drafting increases with speed, and riding $40 \mathrm{~km} / \mathrm{h}$ at the back of eight cyclists reduces $\mathrm{VO}_{2 \max }$ by $39 \%$ [25].

Cycling is a popular sport, and evaluation of the validity of tests to predict performance in competitions is important for athletes and coaches. Similarity between performance in sprints in mass-start bike races and in the laboratory was reported [15], but, to our knowledge, no studies have investigated the relationship between laboratory measurements of $\mathrm{VO}_{2 \max }$ and FTP with performance in mass-start competitions. The high correlation between an outdoor TT and indoor measurement of PPO could indicate that an indoor FTP test will correlate with performance in competitions [11-14]. This correlation between PPO and performance time in a TT was reported in two studies $[6,19]$, both in an uphill TT and a mainly flat TT. In contrast, Balmer, Davison, and Bird [12] found no correlation between the same variables. The use of a power meter (to measure the power produced by cycling or spinning a bike) is popular and widespread among cyclists, making it easy for them to perform an FTP test in their own training area. Therefore, the purpose of this study was to investigate the 
validity of $\mathrm{VO}_{2 \max }$ and power measurements in an FTP test (absolute and relative power) compared to performance in a mass-start mountain bike competition. It was hypothesized that relative power would be the best predictor for performance in a mountain bike competition.

\section{Material and Methods}

\subsection{Participants}

Eleven moderately trained male competitive cyclists (age: $43 \pm 5.1$ years; height: $183.4 \pm 5.4 \mathrm{~m}$; weight: $84.4 \pm 8.7 \mathrm{~kg}$; body mass index $(\mathrm{BMI}): 25.1 \pm 2.1$ ) were recruited from a regional club to participate in the study. The inclusion criteria were a minimum of 2 years of experience in regional cycle competitions and between 200-500 training hours throughout the year. Following an explanation of the procedures, all participants gave written informed consent to participate in the study. The study was conducted according to the Declaration of Helsinki (2013) and approved by the Norwegian centre for Research Data.

\subsection{Testing Procedures}

All participants completed one laboratory testing session and one official mass-start mountain bike competition. In the laboratory test situation, participants performed a structured laboratory protocol that included a standardized 15 min warm-up. After the warm-up, cyclists performed a 20 min TT to determine the FTP [1]. Allen and Coggan [1] have suggested that the FTP60 could be determined as $95 \%$ of the mean power output in a $20 \mathrm{~min}$ TT, and this test was chosen because it is less time-consuming. Therefore, the FTP data in this study are $95 \%$ of the mean power performed in a $20 \mathrm{~min}$ TT. After $5 \mathrm{~min}$ of recovery, an incremental test to exhaustion was performed to determine $\mathrm{VO}_{2 \max }$. This test started with $1 \mathrm{~min}$ of cycling at $20 \mathrm{~W}$ below the average FTP20 value. Workload was subsequently increased by $25 \mathrm{~W}$ every minute until voluntary exhaustion or lack of further increase in $\mathrm{O}_{2}$ uptake. Verbal encouragement was provided throughout the test. $\mathrm{VO}_{2 \max }$ was defined as the average of the two highest $\mathrm{VO}_{2}$ measurements [26]. All participants were familiar with the test situation and completed a minimum of one laboratory test session in which they performed exactly the same tests before the final laboratory test.

The official race was a mass-start $47 \mathrm{~km}$ mountain bike race, where the first $22 \mathrm{~km}$ contained several uphills and the rest was mainly flat or downhill (see Figure 1 for race profile). Total elevation was $851 \mathrm{~m}$. In the official competition, an electronic timing system (emit) was used. Performance in this mass-start $47 \mathrm{~km}$ bike race was tested by a system that included a radiofrequency identification timing tag attached to the participants. A radiofrequency identification reader/controller with antenna assembly (EQ Timing) captured the participants' race time.

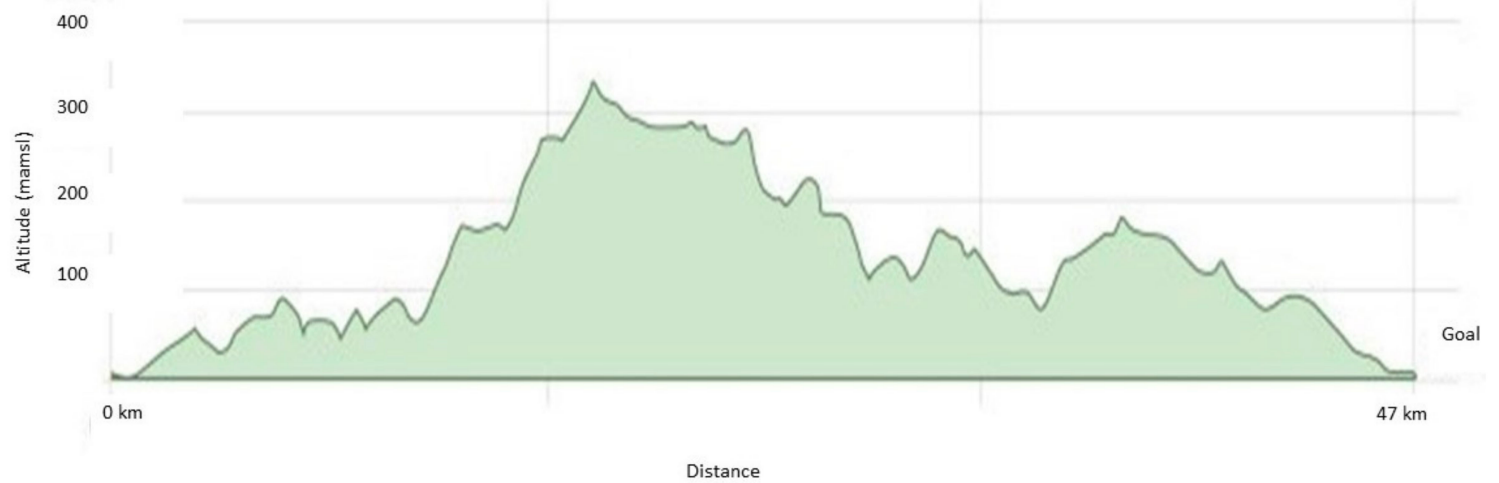

Figure 1. Race profile for the mass-start mountain bike race. Total distance: $47 \mathrm{~km}$. Total elevation: $851 \mathrm{~m}$. Altitude: 3-338 meters above mean sea level (MAMSL). 


\subsection{Instruments}

All tests were conducted under standardized laboratory conditions of $20-22{ }^{\circ} \mathrm{C}$ and $50-60 \%$ relative humidity. Tests were performed on a Tacx Fortius cycle ergometer (Tacx B.V., Wassenaar, Netherlands), which is a stationary power meter that can be used in laboratory conditions. The unit consists of a brushless motor attached to a drum that, when in contact with the rear tire of an individual's bicycle, creates resistance by acting as a generator/dynamo, converting power to alternating current. Before each test, the ergometer was calibrated according to the manufacturer's recommendations. This equipment was scientifically validated and seemingly overestimates power output, but it is stable, and the measurements are reproducible [27]. The saddle height and distance between the tip of the saddle and the bottom bracket were adjusted by each participant as desired. During all laboratory tests, the participants were allowed to choose their preferred cadence.

$\mathrm{VO}_{2}$ was measured using Oxycon Pro (Oxycon: Jaeger GmbH, Hoechberg, Germany) with a mixing chamber and a $30 \mathrm{~s}$ sampling time. Gas sensors were calibrated via an automated process using certified calibration gases of known concentrations $\left(15 \% \mathrm{O}_{2}, 6 \% \mathrm{CO}_{2}\right)$ and atmosphere air before every test. The flow turbine (Triple V, Erich Jaeger, Hoechberg, Germany) was automatically volume-calibrated according to the manufacturer's recommendations.

\subsection{Statistical Analysis}

Data are expressed as mean \pm standard deviation (SD) or as individual values. The distribution of each variable was examined for the assumption of normality using the Kolmogorov-Smirnov test. Correlations were determined using Pearson's product moment correlation coefficient $(r)$. The magnitudes of the correlation coefficients were stratified into groups comprising trivial $(r<0.1)$, small $(0.1<r<0.3)$, moderate $(0.3<r<0.5)$, large $(0.5<r<0.7)$, very large $(0.7<r<0.9)$, nearly perfect $(r>0.9)$, and perfect $(r=1.0)$ [28,29]. The entire statistical analysis was performed using SPSS Statistical Analysis Software for Windows ${ }^{\circledR}$ (SPSS, version 25, Chicago, IL, USA).

\section{Results}

This study found a significant association between mean relative FTP and official race time $(r=0.74, p=0.01)$ (see Figure 2A and Table 1). No significant correlation between any of the other variables was found: $\mathrm{FTP}(\mathrm{W}), \mathrm{VO}_{2 \max }\left(\mathrm{ml} \mathrm{kg}^{-1} \mathrm{~min}^{-1}\right)$, weight $(\mathrm{kg})$, and total time of race competition (min) (see Figure 2B-D and Table 1).

Table 1. Pearson's correlation $(r)$ between performance variables (functional threshold power (FTP), FTP $/ \mathrm{kg}$, maximal oxygen uptake $\left(\mathrm{VO}_{2 \mathrm{max}}\right)$, and race time) in eleven moderately trained competitive cyclists.

\begin{tabular}{ccccc}
\hline $\begin{array}{c}\text { Physical Performance } \\
\text { Variable }\end{array}$ & FTP & FTP/kg & VO $_{\mathbf{2 m a x}}$ & Race Time \\
\hline FTP $(r)$ & 1 & 0.51 & 0.05 & -0.29 \\
FTP $/ \mathrm{kg}(r)$ & 0.51 & 1 & 0.45 & $-0.74^{*}$ \\
$\mathrm{VO}_{2 \max }(r)$ & 0.05 & 0.45 & 1 & -0.37 \\
Race time $(r)$ & -0.29 & $-0.74 *$ & -0.37 & 1 \\
\hline Total mean $\pm \mathrm{SD}$ & $272.8 \pm 29.6$ & $3.3 \pm 0.3$ & $46.3 \pm 4.5$ & $93.1 \pm 6.3$ \\
\hline
\end{tabular}

* Correlation is significant at $p<0.01$ (two-tailed). 

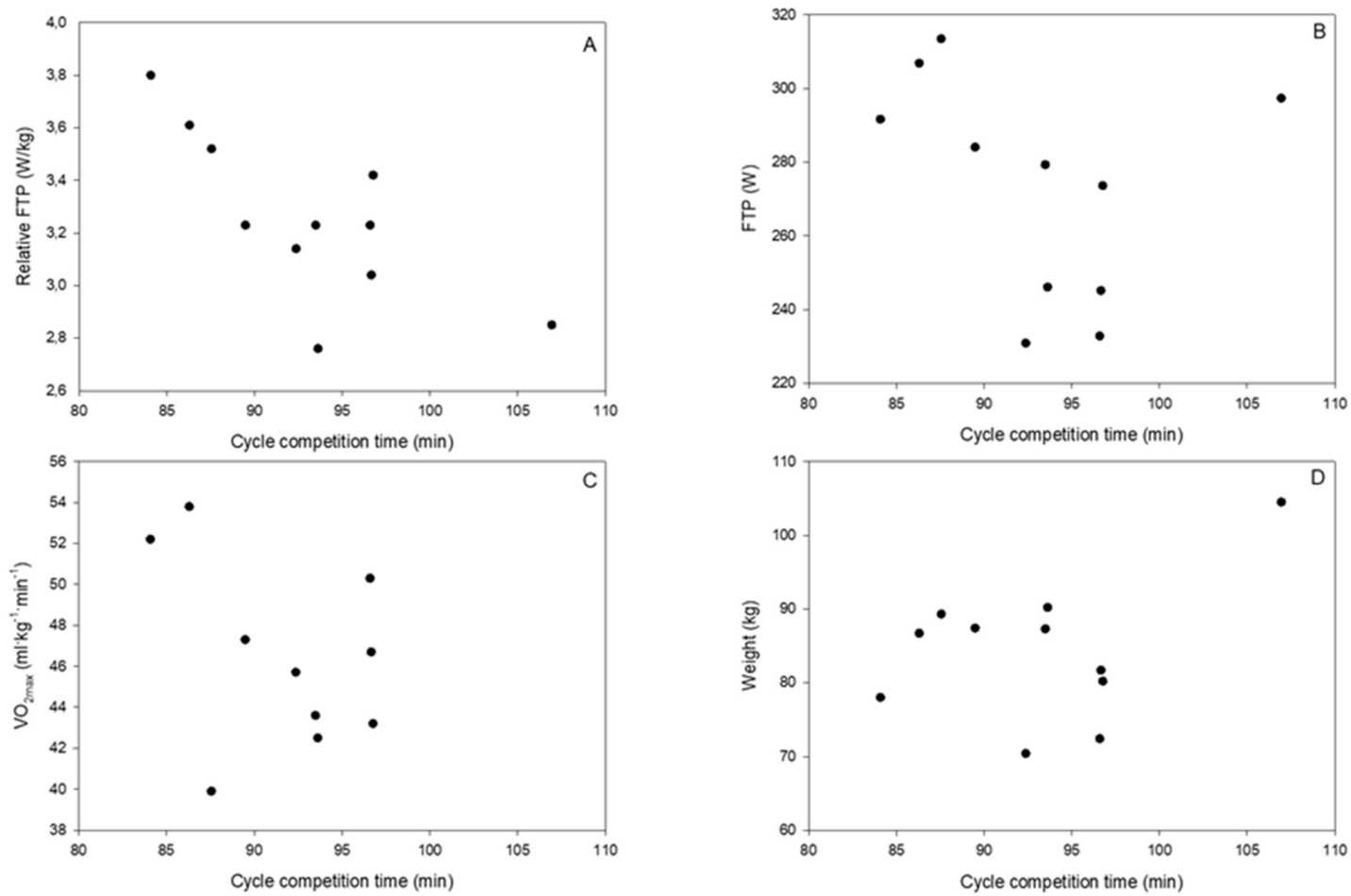

Figure 2. Plots of single sets of XY pairs for (A) relative FTP and race time; (B) FTP and race time; (C) $\mathrm{VO}_{2 \max }$ and race time; and (D) weight and race time, respectively. Each circle indicates one participant.

\section{Discussion}

The purpose of this study was to investigate the validity of $\mathrm{VO}_{2 \max }$ and power measurements in an FTP test (absolute and relative power) compared to performance in a mass-start mountain bike competition. Our main finding indicates a large correlation between FTP relative to body mass $(\mathrm{W} / \mathrm{kg})$ and performance in an official $47 \mathrm{~km}$ mass-start mountain bike race $(\mathrm{r}=-0.74, \mathrm{p}<0.01)$. Secondly, a high $\mathrm{VO}_{2 \max }$ was not associated with reduced time in the official $47 \mathrm{~km}$ mass-start mountain bike race for moderately trained cyclists.

Findings from this study show that results from an FTP test can give moderately trained cyclists important information about their cycling competition performance. High relative power on an indoor $20 \mathrm{~min}$ FTP test is associated with reduced cycling time in the official bike competition. In performance tests such as the FTP test, results depend on physiological ability, as well as work economy and psychological aspects concerning performance. A large correlation between laboratory measurements of absolute power at the lactate threshold (LT) or PPO and mean power in time trials was found in several studies [11-14]. Moreover, a significant relationship between PPO, (both relative and absolute power) and performance time in a mainly flat TT for well-trained cyclists was reported [6], as well as in an uphill TT [20]. For moderately trained cyclists with a mean age of around 40 years, the association between power output and performance time is more uncertain [12]. Lamberts (2011) found that a submaximal cycle test predicted performance time in a $40 \mathrm{~km}$ flat TT [30], whereas Balmer et al. (2000) found absolute peak power in a laboratory test to predict absolute power during an outdoor $16.1 \mathrm{~km}$ TT, but no significant correlation between PPO and performance time [12]. However, some weaknesses were presented in their study with regard to environment standardization and self-selected racing position. They investigated absolute peak power, but an examination of relative power could have given a higher correlation. In the present study, all subjects were able to adjust to a self-selected racing position, and the test situation indoors was standardized. However, in an official competition, many external variables (weather, temperature, environment, and race position) have an influential role in performance time. Laboratory tests often rely on expensive equipment, and affordability can be 
difficult for coaches and athletes. For high-level cyclists, cost or access to this equipment is more realistic than for moderately trained subjects. Therefore, our findings of very large correlations between relative power in the FTP test and cycling time in official competition could give valuable insight for coaches and athletes to monitor the training and performance for this cohort of athletes.

Another important difference between the present study and others investigating associations between power output and a TT is that during a TT, the rules forbid cyclists from drafting, which leads to an individual race against time. A mass start includes more tactical decisions that will possibly play an influential role in the performance. The participants in this study had an average relative FTP of $3.3 \mathrm{~W} / \mathrm{kg}$, which is categorized as a moderate level, while male world-class cyclists have a relative FTP of around 6, well-trained club cyclists have one between 3.5 and 4.5 , and untrained cyclists have one around 2 [1]. This indicates that a good ability to produce high levels of power during competitions is a major determinant in bike races; this is supported by others who show that the difference between cyclists at a high level is not $\mathrm{VO}_{2 \max }$ but their ability to produce power [8].

In the present study, $\mathrm{VO}_{2 \max }$ seems of less importance in order to explain performance in a mass-start cycling competition. Contrary to our findings for moderately trained cyclists, both Borszcz et al. [4] and Denham et al. [5] found $\mathrm{VO}_{2 \max }$ to be a good predictor for performance in moderately trained cyclists. In Denham et al. [5], half of their participants were untrained. In contrast, the cyclists in our study trained $200-500 \mathrm{~h}$ throughout the year, mainly by cycling. In both studies, Denham et al. [5] and the present study, the relative $\mathrm{VO}_{2 \max }$ of the participants was $46 \mathrm{ml} \mathrm{kg}^{-1} \mathrm{~min}^{-1}$, tested by cycling. According to the specificity principle, cycling several hundred hours each year should improve cycling performance but does not necessarily have any impact on the $\mathrm{VO}_{2 \max }$ [31]. The race profile shows that the first $20 \mathrm{~km}$ of the race contained several uphills, while the last $26.7 \mathrm{~km}$ of the race was mostly flat and downhill, and the total elevation was $851 \mathrm{~m}$. The participants in this study had a BMI of 25.1, which could indicate that they had some disadvantage in the first part of the race (mostly uphill) but had an advantage in the last part (mostly flat terrain or downhill) [17]. The best predictors for performance uphill are found by other researchers to be average power output and $\mathrm{VO}_{2 \mathrm{max}}$, both normalized to body mass [21-23]. Therefore, cyclists with a low BMI would benefit when cycling on uphill terrain [17]. Another possible explanation for the low correlation between $\mathrm{VO}_{2 \max }$ and performance time in the mass-start mountain bike race in this study is that performance in competitions is partly dependent on tactical decisions.

No significant relationship was found between absolute FTP and performance. This is not surprising in this type of race, which had a total elevation of $851 \mathrm{~m}$. According to Tan and Aziz [18], high absolute power is important for performance on flat terrain, whereas high relative power is decisive when cycling uphill. Long uphill sections where cyclists must struggle against gravity will be beneficial for cyclists with low body mass [18]. We found no significant correlation between weight and performance. As highlighted before, relative FTP is the decisive factor related to performance, not absolute FTP or weight. If the course in this study had been flat, cyclists with high absolute power production during the FTP test would definitely have performed better in the competition [18].

\section{Practical Implications and Future Research}

The strength of the present study is that relative power produced in a $20 \mathrm{~min}$ FTP test is highly correlated to performance during a mass-start bike race among moderately trained cyclists. The FTP test used in the present study is easy to conduct, both at home and in a community gym, and gives cyclists of different levels a valid test that could help them evaluate and control their training progress. This study also indicates that expensive testing of $\mathrm{VO}_{2 \max }$ in a laboratory is not necessarily cost-effective for moderately trained cyclists.

Generalization of the findings in this study must be done with care, as the sample size of this study only included eleven male cyclists. Therefore, these results have to be interpreted in light of a modest sample size. Moreover, we must keep in mind that the participants were moderately trained, with an average age of 43 years and a BMI of 25.1, so our results cannot be generalized to all other groups of 
cyclists. In addition, performance in a mass-start bike race is not only dependent on physiological issues but also, for example, on tactical ability and psychological factors [25]. However, even though performance time is affected by many factors, high relative power in an FTP test is related to shorter cycling time in this type of cycling competition for this group. During the laboratory test, cyclists had only a $5 \mathrm{~min}$ recovery period after the $20 \mathrm{~min}$ FTP test before taking an incremental test to exhaustion to determine $\mathrm{VO}_{2 \max }$. It is possible that the levels of $\mathrm{VO}_{2 \max }$ could have been higher if this test had been taken the next day, but the ranking between cyclists would probably have been equal.

Future research should evaluate this validity for other types of cycling competitions and for cyclists at different levels and age groups. Furthermore, it would be interesting to evaluate the validity between relative power in an FTP test and cycling performance on flat terrain compared to uphills.

\section{Conclusions}

The present study demonstrate that relative power produced in a 20 min FTP test is highly correlated to performance during a mass-start bike race. However, no significant association was found between either absolute power or relative $\mathrm{VO}_{2 \max }$ and performance in a mass-start mountain bike race.

Author Contributions: Conceptualization, T.D., V.R, A.S. and T.K.A.; Data Curation, T.D, A.S and V.R.; Formal Analysis, T.D and A.S.; Investigation, A.S, T.D and V.R.; Methodology, A.S, T.K.A, V.R and T.D.; Project Administration, A.S and T.D.; Writing-Original Draft, A.S. and T.D.; Writing-Review and Editing, A.S, T.K.A, V.R. and T.D.

Funding: This research received no external funding.

Conflicts of Interest: The authors declare no conflict of interest.

\section{References}

1. Allen, H.; Coggan, A. Training and Racing with a Power Meter, 2nd ed.; Velo Press: Boulder, CO, USA, 2010.

2. Bassett, D.R.; Howley, E.T. Limiting factors for maximum oxygen uptake and determinants of endurance performance. Med. Sci. Sports Exerc. 2000, 32, 70-84. [CrossRef] [PubMed]

3. Faria, E.W.; Parker, D.L.; Faria, I.E. The science of cycling: Physiology and training-Part 1. Sports Med. 2005, 35, 285-312. [CrossRef] [PubMed]

4. Borszcz, F.K.; Tramontin, A.F.; Carminatti, L.J.; Costa, V.P.; Bossi, A.H. Functional threshold power in cyclists: Validity of the concept and physiological responses. Int. J. Sports Med. 2018, 39, 737-742. [PubMed]

5. Denham, J.; Scott-Hamilton, J.; Hagstrom, A.D.; Gray, A.J. Cycling power outputs predict functional threshold power and maximum oxygen uptake. J. Strength Cond. Res. 2017. [CrossRef] [PubMed]

6. Hawley, J.A.; Noakes, T.D. Peak power output predicts maximal oxygen uptake and performance time in trained cyclists. Eur. J. Appl. Physiol. 1992, 65, 79-83. [CrossRef] [PubMed]

7. Whyte, G.; Lumley, S.; George, K.; Gates, P.; Sharma, S.; Prasad, K.; McKenna, W.J. Physiological profile and predictors of cycling performance in ultra-endurance triathletes. J. Sports Med. Phys. Fit. 2000, 40, 103-109.

8. Coyle, E.F.; Feltner, M.E.; Kautz, S.A.; Hamilton, M.T.; Montain, S.J.; Baylor, A.M.; Abraham, L.D.; Petrek, G.W. Physiological and biomechanical factors associated with elite endurance cycling performance. Med. Sci. Sports Exerc. 1991, 23, 93-107. [CrossRef] [PubMed]

9. Bentley, D.J.; McNaughton, L.R.; Thompson, D.; Vleck, V.E.; Batterham, A.M. Peak power output, the lactate threshold, and time trial performance in cyclists. Med. Sci. Sports Exerc. 2001, 33, 2077-2081. [CrossRef]

10. Borszcz, F.K.; Tramontin, A.F.; de Souza, K.M.; Carminatti, L.J.; Costa, V.P. Physiological correlations with short, medium, and long cycling time-trial performance. Res. Q. Exerc. Sport 2018, 89, 120-125. [CrossRef]

11. Nimmerichter, A.; Williams, C.; Bachl, N.; Eston, R. Evaluation of a field test to assess performance in elite cyclists. Int. J. Sports Med. 2010, 31, 160-166. [CrossRef]

12. Balmer, J.; Davison, R.C.R.; Bird, S.R. Peak power predicts performance power during an outdoor 16.1-km cycling time trial. Med. Sci. Sports Exerc. 2000, 32, 1485-1490. [CrossRef] [PubMed]

13. Hiyane, W.C.; Simões, H.G.; Campbell, C.S.G. Critical velocity as a noninvasive method to estimate the lactate minimum velocity on cycling. Rev. Bras. De Med. Do Esporte 2006, 12, 381-385. [CrossRef]

14. Karsten, B.; Jobson, S.A.; Hopker, J.; Jimenez, A.; Beedie, C. High agreement between laboratory and field estimates of critical power in cycling. Int. J. Sports Med. 2014, 35, 298-303. [CrossRef] [PubMed] 
15. Quod, M.J.; Martin, D.T.; Martin, J.C.; Laursen, P.B. The power profile predicts road cycling MMP. Int. J. Sports Med. 2010, 31, 397-401. [CrossRef] [PubMed]

16. Gastin, P.B. Energy system interaction and relative contribution during maximal exercise. Sports Med. 2001, 31, 725-741. [CrossRef] [PubMed]

17. Swain, D.P. The influence of body mass in endurance bicycling. Med. Sci. Sports Exerc. 1994, 26, 58-63. [CrossRef]

18. Tan, F.H.Y.; Aziz, A.R. Reproducibility of outdoor flat and uphill cycling time trials and their performance correlates with peak power output in moderately trained cyclists. J. Sports Sci. Med. 2005, 4, $278-284$.

19. Costa, V.P.; Pertence, L.C.; Paton, C.D.; De Matos, D.G.; Neves Martins, J.A.; De Lima, J.R.P. Physiological correlates of 10-km up-hill cycling performance in competitive cyclists. J. Exerc. Physiol. Online 2011, 14, 26-33.

20. Bossi, A.H.; Lima, P.; Lima, J.P.d.; Hopker, J. Laboratory predictors of uphill cycling performance in trained cyclists. J. Sports Sci. 2017, 35, 1364-1371. [CrossRef]

21. Ahrend, M.; Schneeweiss, P.; Theobald, U.; Niess, A.; Krauss, I. Comparison of laboratory parameters of a mountain bike specific performance test and a simulated race performance in the field. J. Sci. Cycl. 2016, 5, 3-9.

22. Novak, A.R.; Bennett, K.J.M.; Fransen, J.; Dascombe, B.J. Predictors of performance in a 4-h mountain-bike race. J. Sports Sci. 2018, 36, 462-468. [CrossRef] [PubMed]

23. Gregory, J.; Johns, D.P.; Walls, J.T. Relative vs. absolute physiological measure as predictors of mountain bike cross-country race performance. J. Strength Cond. Res. 2007, 21, 17-22. [CrossRef] [PubMed]

24. Impellizzeri, F.M.; Marcora, S.M.; Rampinini, E.; Mognoni, P.; Sassi, A. Correlations between physiological variables and performance in high level cross country off road cyclists. Br. J. Sports Med. 2005, 39, 747-751. [CrossRef] [PubMed]

25. McCole, S.D.; Claney, K.; Conte, J.C.; Anderson, R.; Hagberg, J.M. Energy expenditure during bicycling. J. Appl. Physiol. 1990, 68, 748-753. [CrossRef] [PubMed]

26. Ronnestad, B.R.; Hansen, E.A.; Raastad, T. Effect of heavy strength training on thigh muscle cross-sectional area, performance determinants, and performance in well-trained cyclists. Eur J Appl Physiol. 2010, 108, 965-975. [CrossRef]

27. Bertucci, W. Analysis of the agreement between the Fortius cycling ergometer and the PowerTap powermeter PO during time trials of 6 and 30 min. Comput. Methods Biomech. Biomed. Eng. 2012, 15, 212. [CrossRef]

28. Hopkins, W.G.; Marshall, S.W.; Batterham, A.M.; Hanin, J. Progressive statistics for studies in sports medicine and exercise science. Med. Sci. Sports Exerc. 2009, 41, 3-12. [CrossRef]

29. Cohen, J. Statistical Power Analysis for the Behavorial Sciences, 2nd ed.; Lawrence Erlbaum Associates: Hillsdale, NJ, USA, 1988.

30. Lamberts, R.P. A novel submaximal cycle test to monitor fatigue and predict cycling performance. Br. J. Sports Med. 2011, 45, 797-804. [CrossRef]

31. Sharkey, B.J.; Gaskill, S.E. Sport Physiology for Coaches; Human Kinetics: Champaign, IL, USA, 2006. 